\title{
Paradoxical movement of the lower ribcage at rest and during exercise in COPD patients
}

\author{
A. Aliverti*, M. Quaranta*,\#, B. Chakrabarti", \\ A.L.P. Albuquerque ${ }^{\#, \oplus}$ and P.M. Calverley ${ }^{\#}$
}

ABSTRACT: Paradoxical inward displacement of the costal margin during inspiration is observed in many chronic obstructive pulmonary disease patients at rest but its importance is unclear.

The current authors studied 20 patients (forced expiratory volume in one second $32.6 \pm 11.7$, functional residual capacity $186 \pm 32 \%$ predicted) and 10 healthy controls at rest and during symptom-limited incremental exercise. With optoelectronic plethysmography, the phase shift between pulmonary and abdominal ribcage volumes and the percentage of inspiratory time the ribcage compartments moved in opposite directions were quantified, using control data to define the normal range of movement.

Eight patients showed lower ribcage inspiratory paradox at rest $\left(P_{+}\right)$, while 12 patients did not (P-). This was unrelated to resting lung function or exercise tolerance. Total end-expiratory chest wall volume $\left(E E V_{c w}\right)$ increased immediately when exercise began in $\mathbf{P}+$ patients, but later in exercise in P-patients. This difference in EEVcw was mainly due to a greater increase of endexpiratory pulmonary ribcage volume in $\mathbf{P}+$ patients. During exercise, dyspnoea increased similarly in the two groups, while leg effort increased more markedly in the patients without paradox.

In conclusion, lower ribcage paradox at rest is reproducible and associated with early-onset hyperinflation of the chest wall and predominant dyspnoea at end-exercise. When paradox is absent, the sense of leg effort becomes a more important symptom limiting exercise.

KEYWORDS: Chest wall asynchrony, chronic obstructive pulmonary disease, dyspnoea, exercise, Hoover's sign

$\mathrm{n}$ healthy people, inspiration occurs as a result of the coordinated action of the chest wall muscles. As the diaphragm flattens, the incompressible abdominal contents displace the abdominal wall outwards. The ribcage comprises two linked compartments: the lung-apposed part (pulmonary ribcage $(R C p)$ ), expanded by inspiratory ribcage muscle action and submitted to pleural pressure; and the diaphragm-apposed part (abdominal ribcage ( $\mathrm{RC}$ a)), expanded as this muscle contracts and submitted to abdominal pressure. During inspiration, the expansions of the abdomen and both ribcage compartments are in phase, a relationship that persists when the subject exercises although end-expiratory lung volume is actively reduced by increased expiratory abdominal muscle action [1].
In chronic obstructive pulmonary disease (COPD) the situation is different. Here, the diaphragm is flatter and the respiratory drive is increased [2]. In this condition, the effectiveness of the diaphragm is less than in normal subjects and the expansion of the lower ribcage caused by diaphragmatic contraction is smaller than in normal subjects; consequently, it is possible that an uncoordinated expansion of the two ribcage compartments occurs, leading to ribcage distortion [3, 4]. Before the advent of objective measurements of chest wall volume, clinical observation had identified patients who exhibited paradoxical (inward) movement of their lower ribcage on inspiration [5-8]. Such inspiratory paradoxical motion of the lower ribcage is common in COPD $[7,8]$ and has been proposed
AFFILIATIONS

*TBM Lab, Dipartimento di Bioingegneria, Politecnico di Milano, Milan, Italy.

${ }^{\#}$ Clinical Sciences Centre, University Hospital Aintree, University of Liverpool, Liverpool, UK.

"Federal University of Sao Paulo, Sao Paulo, Brazil.

\section{CORRESPONDENCE}

A. Alivert

TBM Lab

Dipartimento di Bioingegneria

Politecnico di Milano

Piazza Leonardo da Vinci 32

20133 Milan

Italy

Fax: 390223999000

E-mail: andrea.aliverti@polimi.it

Received:

October 262007

Accepted after revision:

September 092008

\section{SUPPORT STATEMENT}

This work was supported by the British Lung Foundation and by a European Respiratory Society (ERS) Training Fellowship (no. 69) A. Aliverti was the recipient of an ERS COPD award

STATEMENT OF INTEREST

A statement of interest for this study can be found at

www.erj.ersjournals.com/misc/ statements.shtml 
as an aid to diagnosis [9]. However, it has not been quantified or related to other forms of respiratory behaviour or the symptoms which limit exercise.

Previously, optoelectronic plethysmography (OEP) has been used to identify differences in the behaviour of the ribcage and abdominal compartments of COPD patients during rest and exercise [10-13]. However, the effect of within-breath asynchrony between different ribcage compartments was not studied. The current authors hypothesised that the presence of lower ribcage paradoxical movement would relate to the pattern of the end-expiratory and end-inspiratory chest wall volume changes during exercise. To test this, the normal range of lower ribcage paradox was defined by studying a group of age-matched healthy controls, and then regional chest wall volumes at rest and during exercise in stable COPD were measured. Additionally, to investigate the relevance of paradoxical lower ribcage movement to exercise undertaken in daily life, exercise performance and symptoms during selfpaced corridor walking were measured.

\section{METHODS \\ Subjects}

In total, 20 male patients who met the clinical and physiological diagnostic criteria for COPD [14] were studied. All patients were or had been tobacco smokers, were $<75$ yrs old and had a post-bronchodilator forced expiratory volume in one second $(\mathrm{FEV} 1) /$ forced vital capacity $(\mathrm{FVC})<0.7$, a prebronchodilator FEV1 $<50 \%$ predicted and showed $<10 \%$ improvement in FEV1 after inhaled bronchodilator drugs. Patients were not known to have paradoxical lower ribcage movement prior to the study and no specific examination for the presence of Hoover's sign $[5,6]$ was undertaken. No patient had experienced a COPD exacerbation requiring treatment in the previous 6 weeks. All were treated with inhaled corticosteroids and long-acting inhaled bronchodilators together with short-acting rescue therapy. In addition, 10 healthy age-matched volunteers were recruited, who followed the same measurement protocol as follows. Subjects had normal spirometry for their age and an FEV1/FVC value $>0.7$.

\section{Protocol}

All assessments were made on a single study day. After clinical review, spirometry and plethysmographic lung volumes were measured in all subjects and repeated in the COPD patients $15 \mathrm{~min}$ after $400 \mu \mathrm{g}$ salbutamol given via a spacer device. Each COPD patient performed two 6-min walking tests with a 20-min rest period between testing. The first walk was used to familiarise the patient with the test and only data from the second walk are reported. After a 20-mins rest, during which the OEP reflective markers were applied, patients were seated on the cycle ergometer and asked to execute three slow vital capacity and three FVC manoeuvres followed by 2 min of quiet breathing (QB), to establish baseline values for the chest wall volumes. After this, subjects undertook the incremental exercise protocol described hereafter. Subject started pedalling, first unloaded for $2 \mathrm{~min}$ and then with an incremental load of $5 \mathrm{~W} \cdot \mathrm{min}^{-1}$ until exhaustion.

The research protocol was approved by the district research ethics committee (Liverpool, UK) and informed consent was obtained from each participant.

\section{Measurements}

Subdivisions of lung volumes were measured to American Thoracic Society (ATS) standards in a body plethysmograph (Medgraphic Autolink 1085D; Medical Graphics, St Paul, MN, USA). Flow was measured at the mouth by a screen pneumotachograph and integrated to display the flow-volume loop from which spirometry and flow indices were derived.

Self-paced corridor walking tests were performed according to standard protocols with a standardised walking course [15]. Subjects walked at their maximal pace along an elliptical $40-\mathrm{m}$ course. They were asked to cover as much ground as possible during the allotted time, while maintaining a steady pace without running. No encouragement was given, and subjects were informed each minute of the time remaining. The patients were allowed to stop, but they could start again, if possible, within the allocated $6 \mathrm{~min}$. Distance covered in $6 \mathrm{~min}$ was recorded, together with oxygen saturation and heart rate (HR) from a lightweight pulse oximeter (Pulsox 300i; Konica Minolta Sensing, Inc., Osaka, Japan). During exercise, subjects were asked to rate their breathlessness and the sense of leg effort every minute on a 10-point modified Borg category scale.

Incremental exercise was performed while seated on an electrically braked cycle ergometer. With the subjects breathing through a mouthpiece with a nose-clip, breath-by-breath ventilatory variables were derived from the flow signal detected by a pneumotachograph system (Medical Graphics). Oxygen consumption and carbon dioxide production were measured using a paramagnetic sensor and infrared carbon dioxide analyser, respectively, as part of an exercise testing system (Medical Graphics). The flow signal was synchronised to that of the motion analyser used for OEP and sent to a personal computer for subsequent analysis. Oxygen saturation was measured by pulse oximetry (Biox 3700e; Ohmeda, Louisville, CO, USA) and cardiac frequency was determined using the R-R interval from a 4-lead ECG. During the exercise tests, subjects were asked to rate their breathlessness and leg effort every minute on the same Borg category scale used in the walking tests.

Kinematics of the chest wall were measured by OEP (OEP System; BTS, Milan, Italy). In brief, the volumes displaced by the three compartments of the chest wall were measured by 89 retro-reflective markers placed on the trunk of the subject according to precise anatomical reference points. Marker positions were captured by six TV cameras (three in front and three behind the subject) operating at 60 frames $\cdot \mathrm{s}^{-1}$ and synchronised with co-axial infrared flashing LEDs. The threedimensional coordinates of the markers were calculated with stereo-photogrammetry and linked with a mesh of triangles to create the surface embedding the trunk. The volume of the trunk enclosed by the surface was obtained through a computing algorithm based on the Gauss' theorem [16].

The markers (fig. 1) were positioned on approximately horizontal rows at the following levels: the clavicular line, the manubrio-sternal joint (angle of Louis), the nipples, the xiphoid process, the lower costal margin, the umbilicus and the anterior superior iliac crest. Surface landmarks for the vertical columns were: the midlines, both anterior and posterior axillary lines, the midpoint of the interval between the midline and the anterior axillary line, the midpoint of the interval between the midline 
and the posterior axillary line, and the midaxillary lines. Extra markers were added bilaterally at the midpoint between the xiphoid and the most lateral portion of the 10th rib, in the region overlying the lung-apposed ribcage, and in corresponding posterior positions. Volume displacement of the chest wall was calculated by triangulating the surface and integrating the subtended volume.

\section{Data analysis}

Modelling of the chest wall

The chest wall was modelled in three compartments: $\mathrm{RC}, \mathrm{RCa}$ and abdomen (AB; fig. 1). Thus, the total volume $(V)$ displaced by the chest wall (CW) was calculated as the sum of the volumes displaced by the individual compartments. The boundaries between the three portions were represented by a transverse section placed at the level of the xiphoid process (between RCp and RCa) and another surface positioned at the level of the lower costal margin (between $\mathrm{RCa}$ and $\mathrm{AB}$; fig. 1). The time-courses of the volume of each region ( $V R C p, V R C a$ and $V \mathrm{ab})$, along with their sum $\left(V_{\mathrm{cw}}\right)$ was processed to obtain a breath-by-breath assessment of both ventilatory pattern and operational chest wall volumes $[1,4,16]$.

Chest wall volume data were standardised for the duration of each test to allow comparisons between different subjects as a percentage of maximum exercise. Comparisons were also made using minute ventilation as a percentage of the maximum value reached and as an absolute value.

Quantitative analysis of the paradoxical movement of the lower ribcage

The presence of paradoxical lower ribcage motion was established by comparing the time-courses of VRCp and VRCa. In each patient, the volume tracings were normalised with respect to time, in order to allow ensemble averaging over three reproducible consecutive breaths randomly chosen within the period of interest (either QB or during exercise at different levels) and to derive an "average" respiratory cycle at each level of workload. Inspiratory and expiratory phases of the breathing cycles were derived from the $V_{\mathrm{cw}}$ signal. From these average breaths, asynchronous and paradoxical motion between the two ribcage compartments were then assessed by calculating the following two parameters (fig. 2).

First, the phase shift $(\theta)$ between $V R C a$ and $V R C p$, as indicated by the degree of opening of the Lissajou figure produced when these two volumes were plotted against each other, was calculated. This was measured as the ratio of the distance delimited by the intercepts of the VRCp versus VRCa dynamic loop on a line parallel to the $x$-axis at $50 \%$ of $R C p$ tidal volume (m), divided by RCa tidal volume (s), as $\theta=\sin ^{-1}\left(\mathrm{~m} \cdot \mathrm{s}^{-1}\right)$, an approach previously adopted [17]. In this system a phase angle of zero represents completely synchronous movement of the compartments and $180^{\circ}$ total asynchrony.

Secondly, inspiratory paradox time (IP), defined as the fraction of the inspiratory time during which the $V \mathrm{RCa}$ decreased (fig. 2), was calculated.

Patients were subdivided into those showing paradox at rest $(\mathrm{P}+)$ and those who did not $(\mathrm{P}-)$. This grouping was based on threshold values of IP and $\theta$, obtained at rest before the various manoeuvres in the 10 healthy volunteers and defined as values two standard deviations beyond the respective means. To confirm the validity of these measurements, three different breaths were selected under the same workload in both the control and COPD subjects and the data compared with the initial estimate. In three COPD patients, the data on the first incremental test were repeated on a subsequent day to
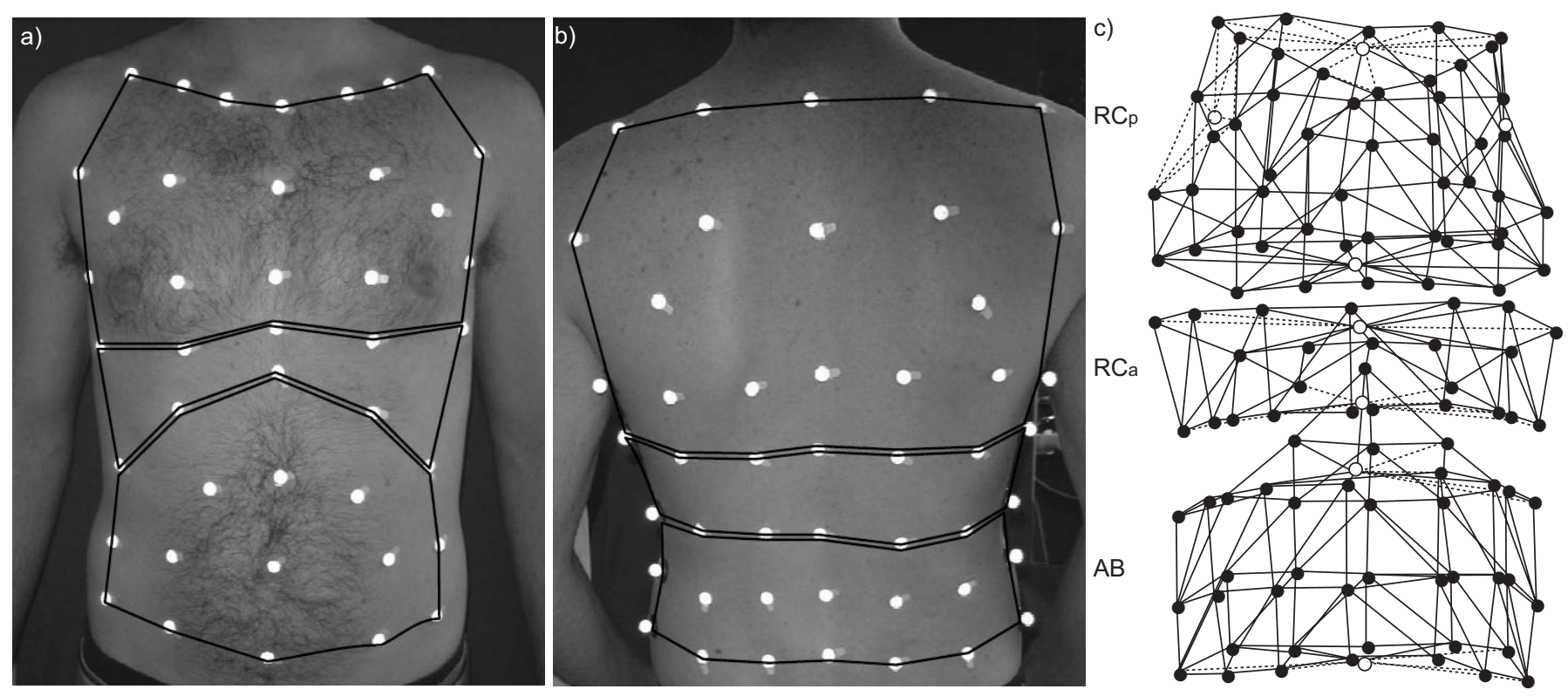

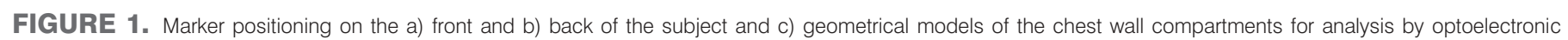

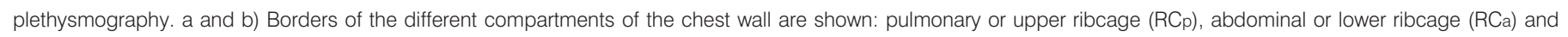

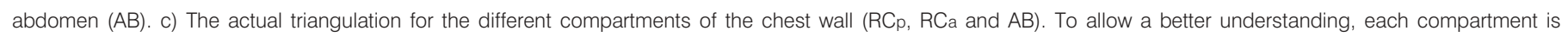
represented slightly shifted in the vertical direction. 

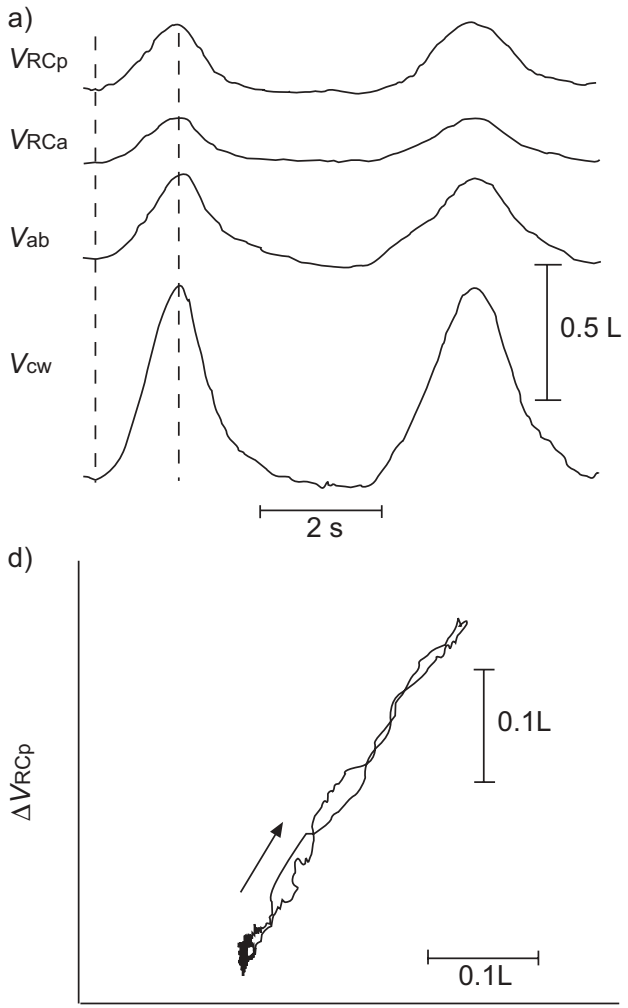

$\Delta V_{\mathrm{RCa}}$

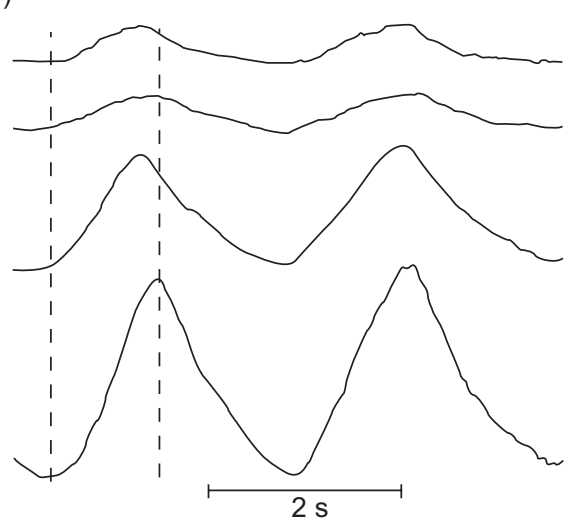

e)

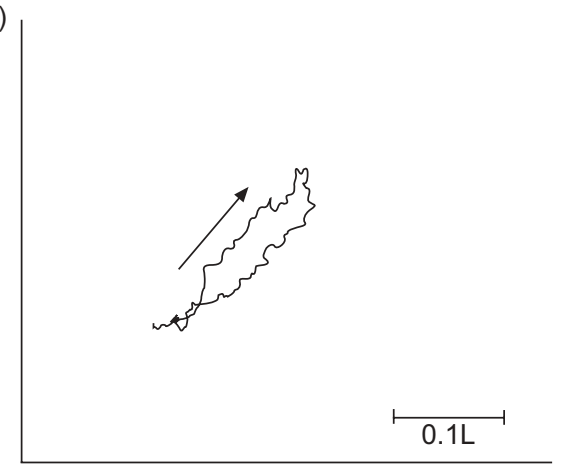

$\Delta V_{\text {RCa }}$ c)
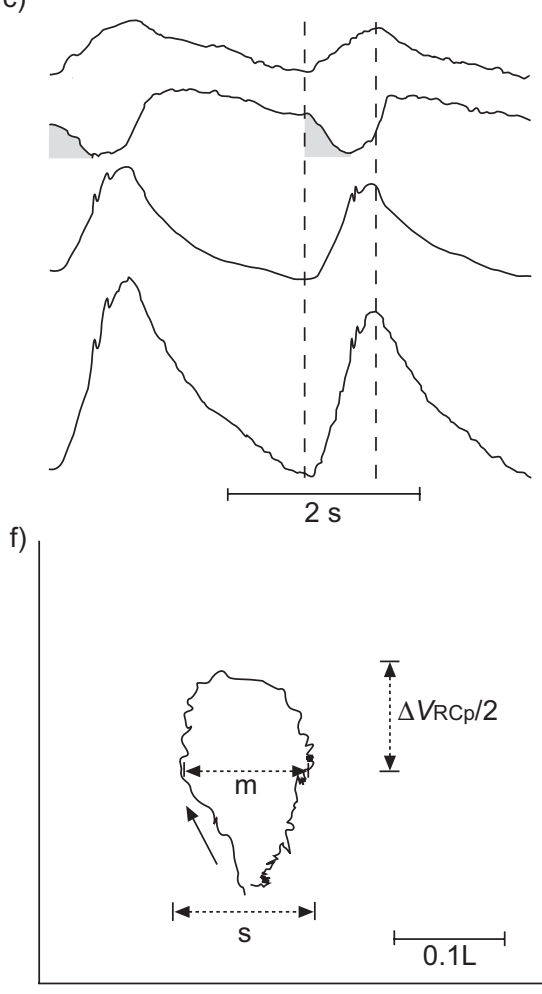

$\Delta$ VRCa

FIGURE 2. a-c) Time-courses of the volumes of the upper ribcage, lower ribcage, abdomen and total chest wall (VRCp, VRCa, Vab and V $\mathrm{cw}$, respectively) during two consecutive breaths at rest. - - - - boundaries of a single inspiration. d-f) Dynamic loops of change ( $\Delta$ ) in $V_{R C p}$ versus $\Delta V_{R C a}$ during quiet breathing, averaged on the respiratory cycle time. Arrows: direction of dynamic loops. a and d) Control subject, b and e) chronic obstructive pulmonary disease (COPD) patient without paradoxical movement between $V_{R C P}$ and $V_{R C a}, \mathrm{C}$ and f) COPD patient with paradoxical movement between VRCp and $V_{R C a}$. 1 : inspiratory paradox time of the lower ribcage. m: line parallel to the $x$-axis at $50 \%$ of $R C p$ tidal volume; $s$ : RCa tidal volume. The phase shift is calculated as $\theta=\sin ^{-1}\left(\mathrm{~m} \cdot \mathrm{s}^{-1}\right)$.

determine whether differences in marker position (positioned by different experimenters) or day-to-day variability in the subjects' breathing influenced the classification of paradoxical movement.

As an alternative parameter to $\theta$ for the quantification of the degree of opening of the Lissajou figure in the $V \mathrm{RCp}-V \mathrm{RCa}$ plot, the hysteresivity index $(\eta)$ was also considered [18]:

$$
\eta=\left((\pi \cdot \Delta V \mathrm{RCp} \cdot \Delta V \mathrm{RCa} / 4 \mathrm{~A})^{2}-1\right)^{-0.5}
$$

where $\Delta V R C p$ and $\Delta V R C a$ are the tidal volumes of the pulmonary and abdominal ribcage, respectively, and $\mathrm{A}$ is the area bounded by the VRCp-VRCa loop.

In a post hoc analysis, the current authors examined whether the presence of tidal expiratory flow limitation at rest was related to the indices of paradoxical lower ribcage movement and the behaviour of patients during exercise. The flow signal was integrated to obtain flow-volume loops during rest, forced expiratory manoeuvres and maximal exercise. To correct the drift of the volume signal obtained from the integration of the flow measured at the mouth, the loops were positioned according to the values of chest wall volume measured at total lung capacity during inspiratory capacity manoeuvres performed at rest before the various manoeuvres during which the loops to be compared were recorded. Expiratory flow limitation was considered present at rest when $>50 \%$ of the tidal breath met or exceeded the expiratory boundary of the maximal flow-volume loop [19].

\section{Statistical analysis}

Data are presented as mean \pm SD unless otherwise stated. Differences between anthropometric, spirometric and exercise data sets were tested using Wilcoxon and Mann-Whitney tests for paired and unpaired data, respectively, with appropriate adjustment for multiple comparisons. To evaluate the influence of ribcage paradox and exercise intensity on ventilatory parameters and operational volumes, a two way ANOVA was performed. Statistical significance was assumed if the nullhypothesis was rejected with a probability of $\mathrm{p}<0.05$.

\section{RESULTS}

Anthropometric characteristics, spirometry values and subdivision of lung volumes are reported in table 1.

\section{Defining the occurrence of paradoxical ribcage movement at rest}

The magnitude of volume change, its timing and the phase angle relationship of the $\mathrm{RC} p$ and $\mathrm{RC}$ a regions are shown for three typical subjects in figure 2, while all the individual $V R C a$ and VRCp time-courses and VRCp-VRCa loops are presented in the online supplementary material. Using a difference of at 


\begin{tabular}{|c|c|c|c|c|}
\hline \multirow[t]{3}{*}{ TABLE 1} & \multicolumn{4}{|c|}{$\begin{array}{l}\text { Patient characteristics: anthropometric } \\
\text { characteristics, spirometric values and } \\
\text { subdivision of lung volumes in chronic } \\
\text { obstructive pulmonary disease (COPD) and } \\
\text { nealthy control subjects }\end{array}$} \\
\hline & \multirow[t]{2}{*}{ Control } & \multicolumn{3}{|c|}{ COPD } \\
\hline & & All & $\mathbf{P}_{+}$ & P- \\
\hline Subjects $n$ & 10 & 20 & 8 & 12 \\
\hline Age yrs & $65 \pm 7$ & $66 \pm 7$ & $69 \pm 6$ & $65 \pm 7$ \\
\hline Height $\mathrm{cm}$ & $173 \pm 6$ & $174 \pm 6$ & $175 \pm 6$ & $173 \pm 7$ \\
\hline Weight kg & $77.0 \pm 7$ & $69 \pm 14$ & $76 \pm 16$ & $63 \pm 11^{*}$ \\
\hline $\mathrm{BMI} \mathbf{k g} \cdot \mathrm{m}^{-2}$ & $25.6 \pm 1.6$ & $22.5 \pm 3.9$ & $24.6 \pm 4.3$ & $21.0 \pm 2.9^{*}$ \\
\hline FVC L & $5.0 \pm 1.29$ & $2.9 \pm 0.78$ & $2.87 \pm 0.77$ & $2.87 \pm 0.83$ \\
\hline FVC \% pred & $117.7 \pm 29.5$ & $66.0 \pm 16.5$ & $65.9 \pm 14.4$ & $66.6 \pm 17.7$ \\
\hline $\mathrm{FEV}_{1} \mathrm{~L}$ & $3.3 \pm 0.5$ & $1.0 \pm 0.3$ & $0.9 \pm 0.2$ & $1.1 \pm 0.4$ \\
\hline FEV $_{1} \%$ pred & $102.8 \pm 12.7$ & $32.6 \pm 11.7$ & $28.0 \pm 6.1$ & $35.6 \pm 13.6$ \\
\hline FEV1/FVC \% & $67.0 \pm 11.6$ & $36.3 \pm 9.4$ & $31.9 \pm 5.7$ & $39.3 \pm 10.4$ \\
\hline FEV1/FVC $\%$ pred & $89.9 \pm 15.2$ & $48.9 \pm 12.6$ & $43.1 \pm 7.9$ & $52.7 \pm 13.9$ \\
\hline TGV L & $3.7 \pm 0.7$ & $6.5 \pm 1.5$ & $6.8 \pm 0.7$ & $6.2 \pm 1.7$ \\
\hline TGV \% pred & $108.6 \pm 20.7$ & $186.4 \pm 31.5$ & $189.1 \pm 24.1$ & $179.1 \pm 34.5$ \\
\hline RV L & $2.9 \pm 0.7$ & $5.6 \pm 1.1$ & $5.7 \pm 0.7$ & $5.4 \pm 1.3$ \\
\hline RV \% pred & $129.9 \pm 29.2$ & $239.5 \pm 48.9$ & $241.2 \pm 35.5$ & $227.9 \pm 49.8$ \\
\hline TLC L & $7.0 \pm 0.9$ & $8.6 \pm 1.4$ & $8.6 \pm 0.9$ & $8.2 \pm 1.5$ \\
\hline TLC \% pred & $106.7 \pm 11.2$ & $125.7 \pm 15.5$ & $126.7 \pm 12.2$ & $123.9 \pm 16.6$ \\
\hline RV/TLC \% & $40.1 \pm 7.4$ & $66.0 \pm 7.2$ & $66.0 \pm 6.0$ & $65.0 \pm 9.1$ \\
\hline RV/TLC \% pred & $124.8 \pm 21.3$ & $188.3 \pm 15.9$ & $184.3 \pm 18.2$ & $194.6 \pm 20.5$ \\
\hline SVC L & $4.2 \pm 0.6$ & $3.0 \pm 0.7$ & $3.0 \pm 0.7$ & $3.0 \pm 0.9$ \\
\hline SvC \% pred & $98.4 \pm 8.9$ & $68.4 \pm 12.1$ & $68.2 \pm 11.1$ & $69.8 \pm 15.1$ \\
\hline IC L & $3.3 \pm 0.6$ & $1.9 \pm 0.4$ & $1.8 \pm 0.5$ & $2.03 \pm 0.3$ \\
\hline IC \% pred & $103.9 \pm 14.7$ & $61.0 \pm 12.3$ & $56.6 \pm 14.3$ & $64.3 \pm 9.9$ \\
\hline
\end{tabular}

Data are presented as mean $\pm S D$, unless otherwise stated. $\mathrm{P}+$ : subjects showing lower ribcage inspiratory paradox at rest; $\mathrm{P}$-: subjects without paradox; BMI: body mass index; FVC: forced vital capacity; \% pred: \% predicted; FEV1: forced expiratory volume in one second; TGV: total gas volume; RV: residual volume; TLC: total lung capacity; SVC: slow vital capacity; IC: inspiratory capacity. *: $\mathrm{p}<0.05$ for comparison of $\mathrm{P}+$ with $\mathrm{P}$ -

least two standard deviations above the mean value for the normal subjects (99\% confidence interval) gave a threshold for the upper limit of normal of 14.0 degrees for phase angle and $20.3 \%$ for the IP. When three different breaths were chosen and the analysis repeated, similar values were obtained and no individual would have been classified as showing ribcage paradox, even if only one criterion were used (see online supplementary material).

Among the COPD patients, eight subjects met both criteria for paradox $(\mathrm{P}+)$ while the remaining 12 did not $(\mathrm{P}-)$. Of these, seven subjects showed no evidence of paradox by either criteria, four showed only an abnormal phase angle and one an increased IP (fig. 3a).

Both indices of paradoxical lower ribcage movement lay close to the upper limit of normal in the P- subjects but were clearly separate from those in the $\mathrm{P}+$ subjects at rest $(\mathrm{p}<0.001$; fig. 4). The reproducibility of the percentage inspiratory time and
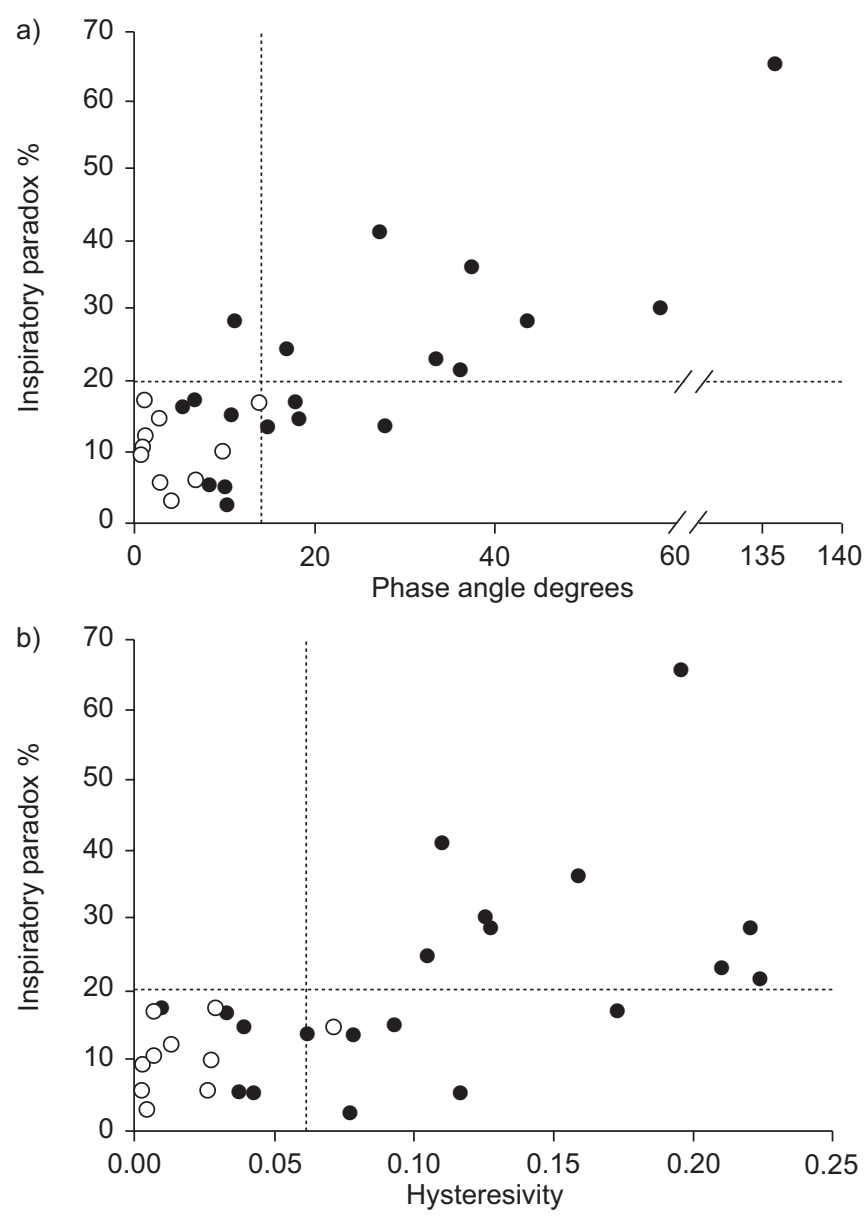

FIGURE 3. a) Relationship between phase of upper versus lower ribcage $(\theta)$ and inspiratory paradox time (IP) of the lower ribcage. b) Relationship between hysteresivity of upper versus lower ribcage $(\eta)$ and IP of the lower ribcage. chronic obstructive pulmonary disease patients; $\bigcirc$ : control subjects. $\cdots$. : thresholds as defined as two standard deviations beyond the mean values observed in healthy subjects at rest. a) Thresholds $\theta=14.0^{\circ}$ and $I P=20.3 \%$, b) thresholds $\eta=0.061$ and $I P=20.3 \%$

phase angle in the COPD patient data was good. No patient would have been reclassified had different breaths been chosen. Likewise, no difference was seen among the replicate data on three different occasions both at rest and during exercise (see online supplementary material).

When $\eta$ was plotted instead of phase angle against IP to investigate ribcage paradox (fig. $3 b$ ), among the COPD patients, nine subjects showed values of both IP and $\eta$ above threshold. Of these, eight subjects were previously classified as $\mathrm{P}+$, and the remaining subject was the one with abovethreshold IP and below-threshold $\theta$.

\section{Tidal expiratory flow limitation}

Among the $\mathrm{P}+$ patients, all showed clear evidence of expiratory flow limitation at rest using the flow-volume criteria (as aforementioned). Among the P-patients, nine out of the 12 were flow limited and three of these flow-limited patients had a value of phase angle above the threshold (see online supplementary fig. E4). 

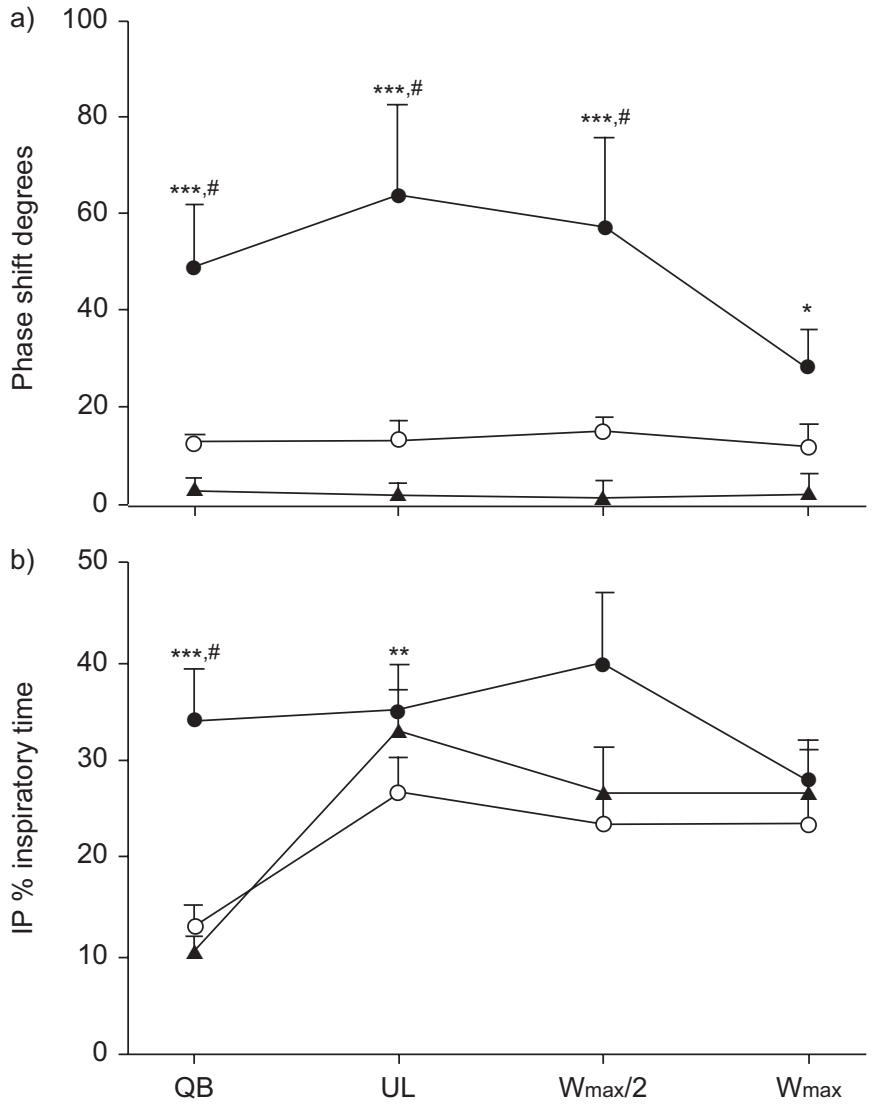

FIGURE 4. Mean \pm SE of a) phase shifts and b) inspiratory paradox times (IP) during exercise between upper (pulmonary) ribcage and lower (abdominal) ribcage. - : chronic obstructive pulmonary disease (COPD) subjects showing lower ribcage inspiratory paradox at rest $(\mathrm{P}+)$; $\mathrm{O}$ : COPD subjects without paradox (P-); $\mathbf{\Lambda}$ : control subjects. QB: quiet breathing; UL: unloaded exercise; Wmax: maximum workload exercise. *: $\mathrm{p}<0.05$ for comparison of $\mathrm{P}+$ with control; $* *: \mathrm{p}<0.01$ for comparison of $\mathrm{P}+$ with $\mathrm{P}_{-} ;{ }^{* * *}: \mathrm{p}<0.001$ for comparison of $\mathrm{P}+$ with $\mathrm{P}_{-} ;{ }^{*}: \mathrm{p}<0.001$ for comparison of $\mathrm{P}+$ with control.

\section{Paradoxical ribcage movement during exercise}

The time-courses of the phase angle and IP during unloaded, half-maximal and maximal exercise are shown in fig. 4. At rest, the $\mathrm{P}+$ group showed, by definition, higher mean phase angle and IP than the P-group. During exercise, the phase angle did not change significantly in the control and the P-groups, but in the $\mathrm{P}+$ group the phase angle fell at maximal exercise so that there was no longer any significant difference between the $\mathrm{P}+$ and the P-groups. The IP patterns, like the phase angle, were similar throughout for the control and P-groups but, unlike the phase angle, increased substantially during exercise, approaching the levels of the $\mathrm{P}+$ group.

\section{Spirometry, lung volumes and exercise performance in COPD}

The presence of ribcage paradox was not associated with statistically significant differences in spirometry or any measurement of resting lung volume when compared with patients who did not show this finding. There were no significant differences in the maximum workload, peak oxygen consumption achieved, maximum minute ventilation or breathing pattern between the two groups of COPD patients (table 2).

\section{Chest wall volumes during incremental exercise}

None of the control subjects showed evidence of an increased end-expiratory total chest wall volume $\left(E E V_{c w}\right)$ at end-exercise relative to their baseline values and all showed an early fall in $\mathrm{EEV}_{\mathrm{cw}}$ as exercise began (fig. 5). In contrast, P+ subjects showed an early increase in $\mathrm{EEV}_{\mathrm{cw}}$ (fig. 6a) and this was maintained up to the maximum workload, exceeding the values of the spontaneous breathing by a mean of $328 \mathrm{~mL}$. In contrast, P- subjects maintained an $\mathrm{EEV}_{\mathrm{cw}}$ similar to the baseline value up to $\sim 50 \%$ of maximum workload. EEV $\mathrm{cw}$ slowly rose thereafter, showing a late hyperinflation of $297 \mathrm{~mL}$ at end-exercise, a value similar to that of the P+ subjects (when volumes were expressed as change from baseline as in figure 6) but statistically different from the healthy volunteers $(p<0.001)$. These findings were similar when data where expressed using minute ventilation either as a percentage of the maximum or as an absolute value (fig. 6b).

The time-course of the end-expiratory and end-inspiratory regional chest wall volumes differed significantly between the healthy subjects and the two COPD groups (fig. 7). In $\mathrm{P}+, \mathrm{RCp}$ end-expiratory volumes rose immediately after the onset of exercise, while this volume increased to a lesser degree in $\mathrm{P}$ and controls $(p<0.001)$. End-expiratory volumes of RCa increased during exercise in a similar way in $\mathrm{P}+$ and $\mathrm{P}$ groups, while in healthy subjects they remained constant up to $\sim 60 \%$ of the maximum workload and then increased on average by $316 \mathrm{~mL}$ at end-exercise. In healthy subjects, the $V \mathrm{ab}$ at end-expiration fell significantly throughout the exercise, while at end-exercise the two COPD groups reached values identical on average to those measured during QB.

\section{Symptoms and self-paced exercise}

Data for the symptom intensity of dyspnoea and leg effort for both incremental and self-paced exercise and total distance walked for both $\mathrm{P}+$ and $\mathrm{P}$ - patients are presented in table 2, while the symptoms at rest, the mid-point of exercise testing and end-exercise are shown in figure 8. The intensity of dyspnoea reported at end-exercise was similar in the two groups with both types of exercise. However, the symptom intensity of leg effort was significantly less in $\mathrm{P}+$ patients during incremental exercise $(p<0.01)$, with a similar trend in the self-paced walk test $(\mathrm{p}<0.05)$. The difference between dyspnoea and sense of leg effort severity was statistically significant in both types of test $(p<0.01)$. Oxygen saturation and HR data did not show significant differences between $\mathrm{P}+$ and $\mathrm{P}$ - groups for either corridor walking or cycling test.

\section{DISCUSSION}

Although the movement of the ribcage during the respiratory cycle normally tracks the change in lung volume, this is not always the case in patients with obstructive lung disease, as has been recognised by clinicians for many years [5, 6]. Magnetometer studies have identified different patterns of behaviour in the upper and lower ribcage $[2,7,8]$ but the present data are the first to provide a quantitative threedimensional assessment of the effect of lower ribcage paradox on chest wall volumes, ventilatory pattern and symptoms at rest and during exercise. It was observed that COPD patients 
TABLE 2 Resting and end-exercise ventilatory pattern and metabolic and cardiac variables

\begin{tabular}{|c|c|c|c|c|c|c|c|c|}
\hline & \multicolumn{2}{|c|}{ Control } & \multicolumn{2}{|c|}{ All } & \multicolumn{2}{|c|}{$\mathbf{P}+$} & \multicolumn{2}{|c|}{ P- } \\
\hline Subjects $n$ & \multicolumn{2}{|c|}{10} & \multicolumn{2}{|c|}{20} & \multicolumn{2}{|c|}{8} & \multicolumn{2}{|c|}{12} \\
\hline$V^{\prime} E L \cdot \min ^{-1}$ & $11.4 \pm 2.7$ & $67.40 \pm 17.20$ & $16.34 \pm 3.59$ & $40.54 \pm 8.92$ & $16.65 \pm 3.25$ & $42.00 \pm 9.38$ & $16.13 \pm 3.92$ & $39.58 \pm 8.89$ \\
\hline$t ı s$ & $1.50 \pm 0.26$ & $1.04 \pm 0.19$ & $1.07 \pm 0.29$ & $0.87 \pm 0.38$ & $1.03 \pm 0.27$ & $0.79 \pm 0.29$ & $1.11 \pm 0.32$ & $0.94 \pm 0.45$ \\
\hline Duty cycle \% & $39.6 \pm 6.0$ & $46.2 \pm 2.5$ & $35.6 \pm 5.4$ & $39.8 \pm 5.8$ & $34.7 \pm 5.6$ & $39.4 \pm 5.3$ & $36.1 \pm 5.6$ & $40.1 \pm 6.5$ \\
\hline$V^{\prime} \mathrm{O}_{2} L \cdot \min ^{-1}$ & $0.33 \pm 0.10$ & $1.75 \pm 0.42$ & $0.32 \pm 0.06$ & $0.78 \pm 0.19$ & $0.34 \pm 0.0$ & $0.75 \pm 0.18$ & $0.31 \pm 0.07$ & $0.80 \pm 0.20$ \\
\hline$V^{\prime} \mathrm{O}_{2} \mathrm{~mL} \cdot \mathrm{kg}^{-1} \cdot \mathrm{min}^{-1}$ & $4.45 \pm 1.57$ & $22.73 \pm 5.02$ & $4.56 \pm 1.31$ & $11.08 \pm 3.16$ & $4.69 \pm 1.29$ & $10.37 \pm 2.59$ & $4.48 \pm 1.37$ & $11.55 \pm 3.52$ \\
\hline$V^{\prime} \mathrm{CO}_{2} \mathrm{~L} \cdot \mathrm{min}^{-1}$ & $0.27 \pm 0.07$ & $2.19 \pm 0.59$ & $0.28 \pm 0.06$ & $0.77 \pm 0.19$ & $0.30 \pm 0.05$ & $0.74 \pm 0.18$ & $0.27 \pm 0.06$ & $0.78 \pm 0.21$ \\
\hline Dyspnoea & $0 \pm 0.0$ & $4.4 \pm 3.8$ & $0.7 \pm 0.2$ & $4.0 \pm 1.1$ & $0.9 \pm 0.9$ & $3.9 \pm 0.8$ & $0.7 \pm 0.7$ & $4.1 \pm 1.2$ \\
\hline Sense of leg effort & $0 \pm 0.0$ & $5 \pm 3.6$ & $0.5 \pm 0.2$ & $4.3 \pm 1.6$ & $0.5 \pm 0.9$ & $3.7 \pm 1.6$ & $0.5 \pm 0.77$ & $4.7 \pm 1.4^{\star *}$ \\
\hline $\begin{array}{l}\text { Predominant } \\
\text { symptom }^{\#}\end{array}$ & $0 \pm 0.0$ & $-0.6 \pm 0.6$ & $0.2 \pm 0.1$ & $-0.3 \pm 0.2$ & $0.4 \pm 0.7$ & $0.3 \pm 1.2$ & $0.2 \pm 0.4$ & $-0.7 \pm 0.7^{\star *}$ \\
\hline Maximum workload W & \multicolumn{2}{|c|}{$153 \pm 35$} & \multicolumn{2}{|c|}{$43 \pm 19$} & \multicolumn{2}{|c|}{$42 \pm 20$} & \multicolumn{2}{|c|}{$44 \pm 19$} \\
\hline $\begin{array}{l}\text { 6-min walking } \\
\text { distance } \mathrm{m}\end{array}$ & & & \multicolumn{2}{|c|}{$291 \pm 12$} & \multicolumn{2}{|c|}{$290 \pm 93$} & \multicolumn{2}{|c|}{$291 \pm 63$} \\
\hline
\end{tabular}

Data are expressed as mean \pm SD. COPD: chronic obstructive pulmonary disease; $\mathrm{P}+$ : subjects showing lower ribcage inspiratory paradox at rest; $\mathrm{P}$-: subjects without paradox; fR: respiratory frequency; $V T$ : tidal volume; $V^{\prime} E$ : minute ventilation; tl: inspiratory time; $V^{\prime} \mathrm{O}_{2}$ : oxygen consumption; $V^{\prime} \mathrm{CO}_{2}$ : carbon dioxide production; RER: respiratory exchange ratio; $P \mathrm{ET}, \mathrm{CO}_{2}$ : end-tidal carbon dioxide tension; $\mathrm{Sa}, \mathrm{O}_{2}$ : arterial oxygen saturation. ${ }^{\#}$ : dyspnoea minus leg effort. ${ }^{* *}: \mathrm{p}<0.01$ for comparison of $\mathrm{P}+$ with P-. $1 \mathrm{mmHg}=0.133 \mathrm{kPa}$.

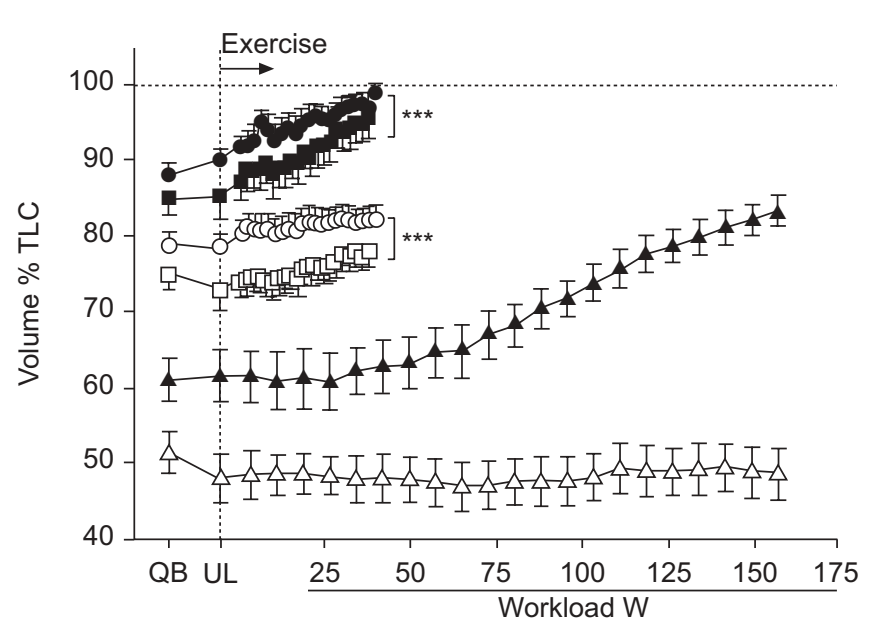

FIGURE 5. Mean \pm SE end-expiratory (EE) and end-inspiratory (El) total chest wall volume variations during exercise, expressed as percentage of the chest wall volume at total lung capacity (TLC), in chronic obstructive pulmonary disease (COPD) patients and control subjects. $\bullet$ : COPD subjects showing lower ribcage inspiratory paradox at rest $(\mathrm{P}+), \mathrm{El} ; \mathbf{\square}$ : COPD subjects without paradox (P-), El; O: P+, EE; $\square$ : P-, EE; $\mathbf{\Lambda}$ : control subjects, El; $\triangle$ : control subjects, EE. QB: quiet breathing; UL: unloaded exercise. ${ }^{* \star}: \mathrm{p}<0.001$ for comparison of $\mathrm{P}+$ with $\mathrm{P}$ (overall data). with paradox increased their $\mathrm{EEV}_{\mathrm{cw}}$ as soon as exercise began, while those without lower ribcage paradox only hyperinflated their chest wall towards the end of incremental exercise. These changes were reflected in the symptoms reported during exercise, with dyspnoea being the major complaint when paradox was present, irrespective of whether the exercise was incremental or self-paced. This suggests that different patterns in the timing of $\mathrm{EEV}_{\mathrm{cw}}$ change [12] relate to patient symptoms and can be reliably predicted by ribcage movement assessed under resting conditions.

In the present study, paradoxical ribcage movement was defined by quantifying the asynchrony between the two ribcage regions during inspiration. The current authors followed the model proposed by WARD et al. [20] and used by others reporting data with OEP $[1,4]$, in which the ribcage is considered as formed by two subcompartments, i.e. the part that is apposed to the lung, the $\mathrm{RCp}$, and the part apposed to the diaphragm, the RCa. The boundary between the $R C p$ and the RCa was defined by a surface identified by a set of markers placed at the level of the xiphisternum (fig. 1), which does not change with diaphragm movement. Thus, in COPD patients, the VRCa may not precisely correspond to the true area of apposition but is best considered as representing the lower ribcage where the muscles inserted and acting in that area differ from those influencing upper ribcage volume. 

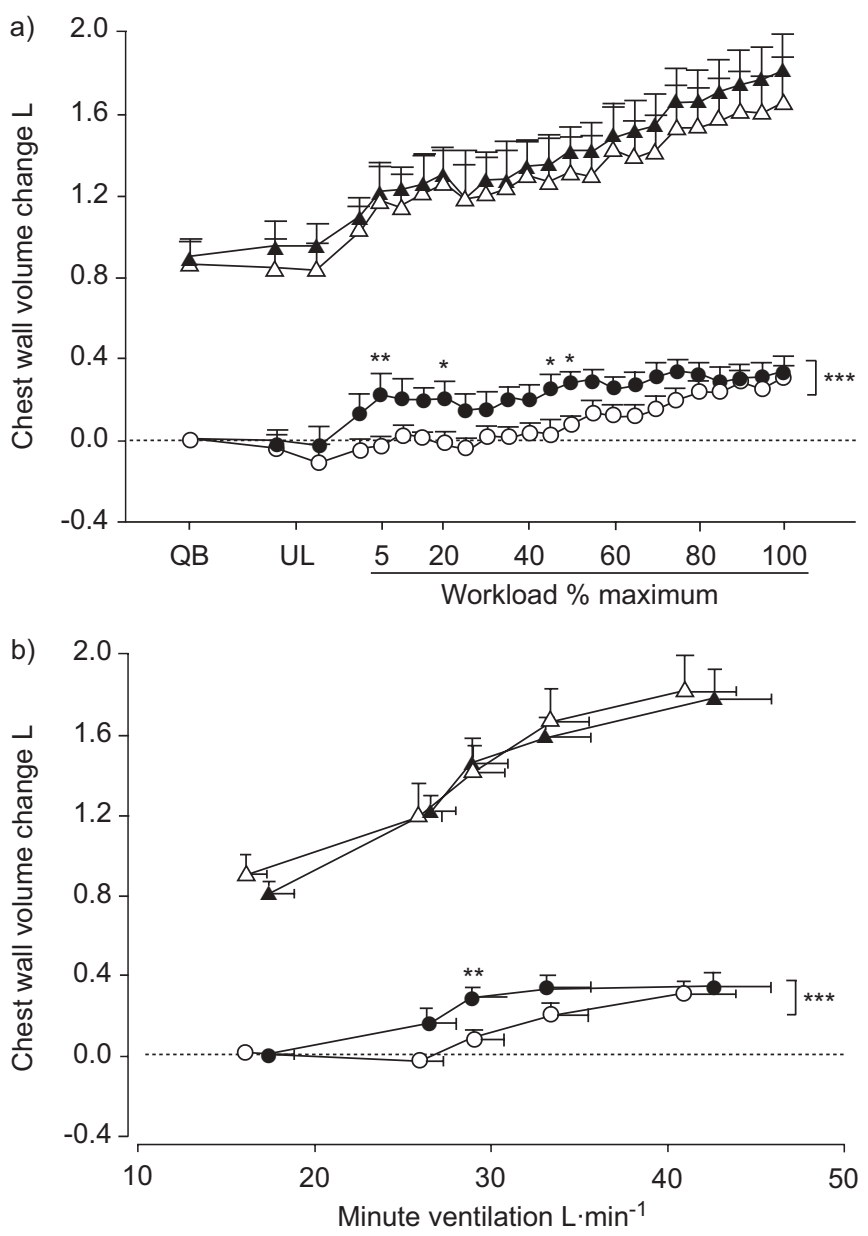

FIGURE 6. Mean \pm SE end-expiratory (EE) and end-inspiratory (EI) total chest wall volume variations during exercise, expressed as chest wall volume variations at functional residual capacity during quiet breathing (QB) in the chronic obstructive pulmonary disease (COPD) patients as a function of a) workload and b) minute ventilation. $\mathbf{\Delta}$ : COPD subjects showing lower ribcage inspiratory paradox at rest $(\mathrm{P}+), \mathrm{El} ; \triangle$ : COPD subjects without paradox (P-), El; $\bullet: \mathrm{P}+, \mathrm{EE} ; \mathrm{O}: \mathrm{P}-, \mathrm{EE} . \mathrm{UL}$ : unloaded exercise. ${ }^{*}: \mathrm{p}<0.05$ for comparison of $\mathrm{P}+$ with $\mathrm{P}$ - (at same level of exercise); ${ }^{* *}: \mathrm{p}<0.01$ for comparison of $\mathrm{P}+$ with $\mathrm{P}$ - (at same level of exercise); ${ }^{* * *}$ : $\mathrm{p}<0.001$ for comparison of $\mathrm{P}+$ with $\mathrm{P}$ - (overall data).

While previous studies have used changes in the lateral and antero-posterior dimensions of the ribcage to do this $[7,8]$, the present approach was based on the analysis of volume variation, obtained by integrating the three-dimensional motion of multiple surface markers. Thus, the current data are not strictly comparable with those obtained by twodimensional analysis of lower ribcage movement alone, and they provide a description of normal or paradoxical inspiratory motion that includes and integrates changes of dimensions in multiple directions. A conservative definition of paradox based on the relative movement of the upper and lower ribcage regions was used, which was only considered to be significant when there were changes beyond the normal range in both the percentage of inspiratory time where paradox was seen and in the phase angle shift. The latter index provided a measure of the degree of chest wall distortion while the former indicated how much of the inspiratory period was affected. It was possible to classify individuals in a binary fashion, although the variables themselves are likely to represent a continuous spectrum of severity as can be seen in figure 3 and supplementary table E1. Each of these measurements proved relatively reproducible in both healthy subjects and those with COPD when different breaths were ensembleaveraged to generate the data. Moreover, differences in individual operators positioning the markers on different days did not influence the results, nor did the classification of resting paradoxical ribcage movement change if different breaths were used to define it.

When a different index like the hysteresivity of the $V \mathrm{RCp}-\mathrm{VRCa}$ loop was considered instead of the phase shift angle, the classification did not change substantially. Only one patient who previously showed an increased percentage inspiratory paradox without an apparently abnormal phase angle shift would have been reclassified as belonging to the $\mathrm{P}+$ group. Interestingly, this patient showed relatively early onset of chest wall hyperinflation during exercise.

The present data were primarily observational rather than mechanistic. Like the investigators who identified Hoover's sign clinically $[9,21]$, the current authors found no relationship between the presence of lower ribcage paradox and resting lung function. The only significant differences found between $\mathrm{P}+$ and $\mathrm{P}$ - groups were for weight and body mass index, suggesting that paradox may be commoner as weight increases. This needs to be confirmed in a larger population of patients. However, a selective activation of different respiratory muscle groups might explain the relationship between the presence of ribcage paradox at rest and the increased end-expiratory $V R C p$ at the onset of exercise in the $\mathrm{P}+$ subjects. These patients may exhibit an increase in ribcage and related accessory muscle tonic activation. More detailed studies to understand the basis of resting paradox defined as in the present study are now underway. Future experiments are needed in order to correlate paradoxical movement of the lower ribcage to diaphragm shape and length of the area of apposition, as recently proposed by preliminary studies based on ultrasound [2, 22, 23] and magnetic resonance [24] imaging.

Exercise modified the different components of paradox in different ways. In controls and P- COPD subjects, the phase angle was unchanged by exercise, while in $\mathrm{P}+$ patients it only decreased at maximum workload, but even then did not reach the values seen in the healthy subjects and P- COPD patients. This result may reflect the increasing volume, and therefore decreasing compliance, of the RCp as hyperinflation develops, with a concomitant increase in the mechanical linkage between the two ribcage portions. In contrast, in the control and Psubjects, the percentage of inspiratory paradox time tended to increase at the onset of exercise and to remain constant thereafter, approaching levels similar to those seen in the P+ group. This result may be attributed to the insertional action of the expiratory abdominal muscles on the lower ribcage [1, 4], even though end-expiratory $V$ ab decreased substantially only at the onset and during exercise in the healthy subjects (fig. 7).

All the $\mathrm{P}+$ patients showed an early increase of $\mathrm{EEV}_{\mathrm{cw}}$. This was mainly due to the increase of the $V \mathrm{RCp}$, presumably to cope with the expiratory action of the lower ribcage, which was not seen in 

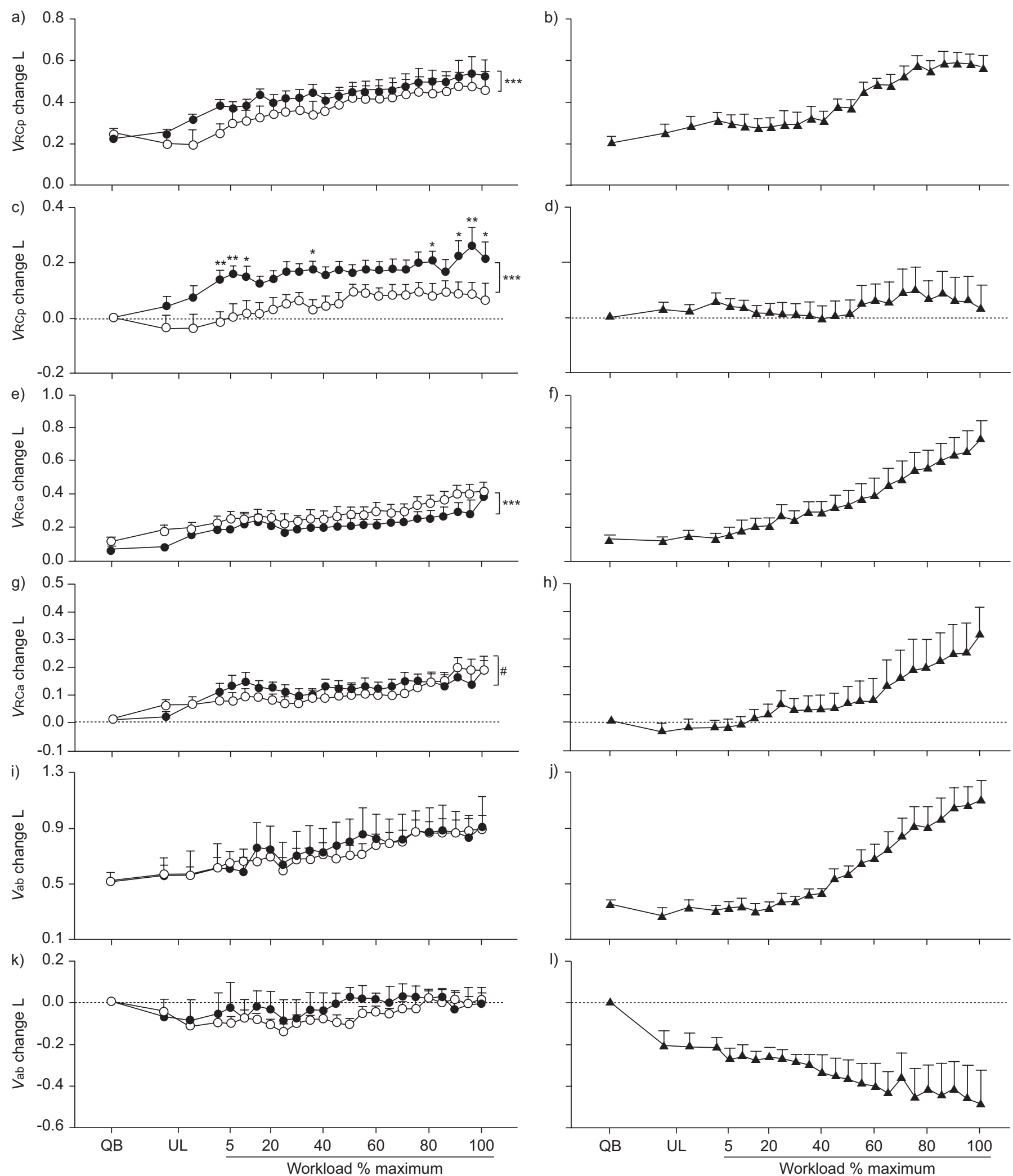

FIGURE 7. Mean \pm SE end-inspiratory ( $a, b, e, f, i$ and j) and end-expiratory ( $c, d, g, h, k$ and I) volume variations of the upper ribcage (VRCp; a-d), lower ribcage (VRCa; eh) and abdomen (Vab; i-l) during exercise in the chronic obstructive pulmonary disease (COPD; a, c, e, g, i and k) and control groups (b, d, f, h, jand I). All volumes refer to the corresponding values at functional residual capacity during quiet breathing $(\mathrm{QB})$. $\bullet$ : COPD subjects showing lower ribcage inspiratory paradox at rest $(\mathrm{P}+)$; $\bigcirc$ : COPD subjects without paradox (P-); $\mathbf{\Lambda}$ : control subjects. UL: unloaded exercise. *: $p<0.05$ for comparison of $\mathrm{P}+$ with $\mathrm{P}$ - (at same level of exercise); ${ }^{* *}$ : $p<0.01$ for comparison of $\mathrm{P}+$ with $\mathrm{P}$ - (at same level of exercise); ${ }^{\star * *}: \mathrm{p}<0.001$ for comparison of $\mathrm{P}+$ with $\mathrm{P}$ - (overall data); ${ }^{*}: \mathrm{p}<0.05$ for comparison of $\mathrm{P}+$ with $\mathrm{P}$ - (overall data). 

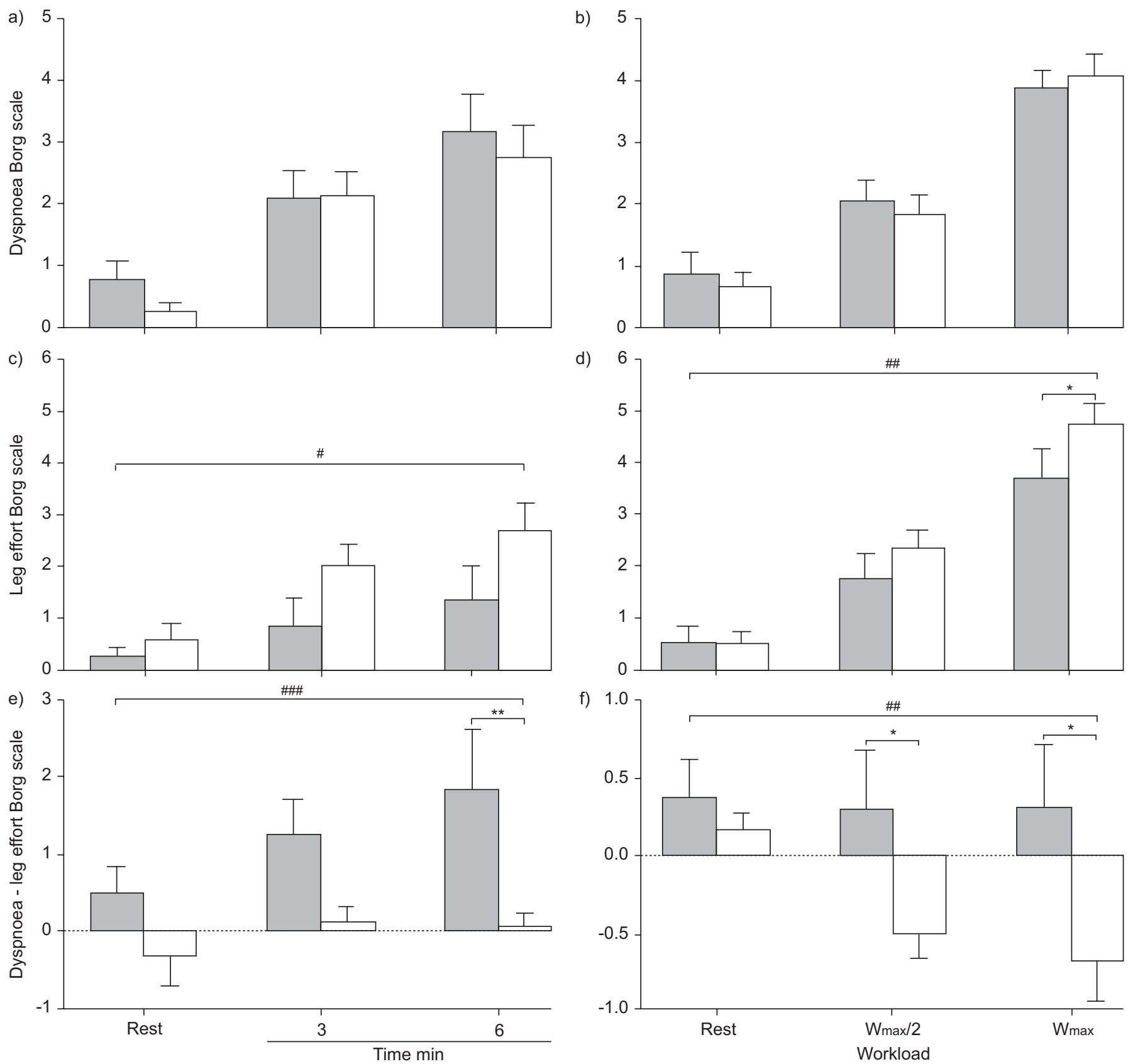

FIGURE 8. $a$ and b) Dyspnoea, $c$ and d) leg effort and e and f) difference between the two symptoms (dyspnoea minus leg effort) during the 6-min walking test (a, $c$ and e) and exercise ( $b, d$ and $f)$. Data are presented as mean \pm SE. $\mathbf{m}$ : chronic obstructive pulmonary disease (COPD) subjects showing lower ribcage inspiratory paradox at rest $(P+)$; $\square$ : COPD subjects without paradox $(P-)$. Wmax: maximum workload exercise. ${ }^{*}: p<0.05$ for comparison of $P+$ with $P$ - (at same level of exercise); ${ }^{*}$ : $p<0.01$ for

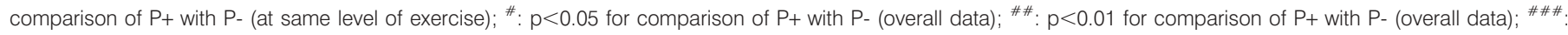
$\mathrm{p}<0.001$ for comparison of $\mathrm{P}+$ with $\mathrm{P}$ - (overall data).

the P-patients. The early onset of chest wall hyperinflation in $\mathrm{P}+$ patients was unexpected and was not related to the duration of exercise or the severity of airflow obstruction or baseline pulmonary hyperinflation. Retrospective classification of the presence of tidal expiratory flow-limitation showed that all the eight $\mathrm{P}+$ patients were flow-limited compared with nine out of the $12 \mathrm{P}$ - patients. None of the P-patients exhibited chest wall hyperinflation at the onset of exercise. These results suggest that paradoxical motion rather than the presence of tidal expiratory flow-limitation determines early chest wall hyperinflation.
Breathlessness and sense of leg effort increased during exercise in patients with and without ribcage paradox, although the relative importance of each symptom differed. At the end of cycle exercise, end-inspiratory $V_{\mathrm{cw}}$, which is not influenced by gas compression and blood shift effects, approached the critical inspiratory reserve volume associated with neuromechanical dissociation [25] in both groups. However, the P+ patients were less likely to report severe sense of leg effort than the Ppatients, with breathlessness being their principal complaint at the end of exercise. This is in keeping with previous reports of 
symptom limitation in severe COPD [26], and the predominance of effort in P- subjects was replicated during the selfpaced corridor testing. These differences were not related to degree of oxygen desaturation, peak workload or exercise duration. The early onset of dynamic hyperinflation of the chest wall is the most likely explanation for the predominance of dyspnoea in $\mathrm{P}+$ patients. In P-patients other factors, such as the onset of peripheral muscle fatigue that limits exercise in some COPD patients, may have been more important [27].

The present study was designed to identify reliable objective criteria for the presence of paradoxical lower ribcage movement and test whether these could be used to predict physiological differences during exercise in stable hyperinflated COPD patients. Although the criteria resemble the subjective ones described by HOOVER [6], the current patients were not selected on the basis of a clinical diagnosis of Hoover's sign and this was not recorded, to avoid the risk of biasing the results. Other studies have examined resting lower ribcage movement using the OEP method in patients clinically defined as having Hoover's sign, and have reported that Hoover's sign did not correlate with the level of hyperinflation and, therefore, ribcage distortion and hyperinflation appear to be independent factors limiting ventilatory function in stable COPD patients [21].

In conclusion, the present study has shown that abnormal lower ribcage movement is not just a clinical curiosity but that it identifies important physiological differences in the chest wall volumes during exercise and these translate into different patterns of reported symptoms. The early onset of hyperinflation in those with paradox helps to explain why differences seen in incremental exercise are still present during lowerintensity self-paced exercise, which relates to the daily activity undertaken by chronic obstructive pulmonary disease patients.

\section{ACKNOWLEDGEMENTS}

Part of this work has been presented as a poster (A. Aliverti, M. Quaranta, B. Chakrabarti, P.M. Calverley. Hoover's sign, dynamic hyperinflation and dyspnoea during exercise in COPD) at the ATS International Conference, San Francisco, May 2007.

\section{REFERENCES}

1 Aliverti A, Cala SJ, Duranti R, et al. Human respiratory muscle actions and control during exercise. J Appl Physiol 1997; 83: 1256-1269.

2 Gorman RB, McKenzie DK, Pride NB, Tolman JF, Gandevia SC. Diaphragm length during tidal breathing in patients with chronic obstructive pulmonary disease. Am J Respir Crit Care Med 2002; 166: 1461-1469.

3 Chihara K, Kenyon CM, Macklem PT. Human rib cage distortability. J Appl Physiol 1996; 81: 437-447.

4 Kenyon CM, Cala SJ, Yan S, et al. Rib cage mechanics during quiet breathing and exercise in humans. J Appl Physiol 1997; 83: 1242-1255.

5 Stokes W. A Treatise on the Diagnosis and Treatment of Diseases of the Chest. Part 1. Diseases of the lung and windpipe. London, The New Sydenham Society, 1837; pp. 168-169.

6 Hoover CF. The diagnostic significance of inspiration movement of the costal margins. Am J Med Sci 1920; 159: 633-645.
7 Gilmartin JJ, Gibson GJ. Abnormalities of chest wall motion in patients with chronic airflow obstruction. Thorax 1984; 39: 264-271.

8 Gilmartin JJ, Gibson GJ. Mechanisms of paradoxical rib cage motion in patients with chronic obstructive pulmonary disease. Am Rev Respir Dis 1986; 134: 683-687.

9 Garcia-Pachon E. Paradoxical movement of the lateral rib margin (Hoover sign) for detecting obstructive airway disease. Chest 2002; 122: 651-655.

10 Aliverti A, Stevenson N, Dellacà RL, Lo Mauro A, Pedotti A, Calverley PM. Regional chest wall volumes during exercise in chronic obstructive pulmonary disease. Thorax 2004; 59: 210-216.

11 Aliverti A, Rodger K, Dellacà RL, et al. Effect of salbutamol on lung function and chest wall volumes at rest and during exercise in COPD. Thorax 2005; 60: 916-924.

12 Vogiatzis I, Georgiadou O, Golemati S, et al. Patterns of dynamic hyperinflation during exercise and recovery in patients with severe chronic obstructive pulmonary disease. Thorax 2005; 60: 723-729.

13 Georgiadou O, Vogiatzis I, Stratakos G, et al. Effects of rehabilitation on chest wall volume regulation during exercise in COPD patients. Eur Respir J 2007; 29: 284-291.

14 Standards for the diagnosis and care of patients with chronic obstructive pulmonary disease. American Thoracic Society. Am J Respir Crit Care Med 1995; 152: S77-S121.

15 Brooks D, Solway S, Gibbons WJ. ATS statement on sixminute walk test. Am J Respir Crit Care Med 2003; 167: 1287.

16 Cala SJ, Kenyon CM, Ferrigno G, et al. Chest wall and lung volume estimation by optical reflectance motion analysis. J Appl Physiol 1996; 81: 2680-2689.

17 Agostoni E, Mognoni P. Deformation of the chest wall during breathing efforts. J Appl Physiol 1966; 21: 1827-1832.

18 Fredberg JJ, Stamenovic D. On the imperfect elasticity of lung tissue. J Appl Physiol 1989; 67: 2408-2419.

19 Johnson BD, Weisman IM, Zeballos RJ, Beck KC. Emerging concepts in the evaluation of ventilatory limitation during exercise: the exercise tidal flow-volume loop. Chest 1999; 116: 488-503.

20 Ward ME, Ward JW, Macklem PT. Analysis of human chest wall motion using a two-compartment rib cage model. J Appl Physiol 1992; 72: 1338-1347.

21 Binazzi B, Bianchi R, Romagnoli I, et al. Chest wall kinematics and Hoover's sign. Respir Physiol Neurobiol 2008; 160: 325-333.

22 Singh B, Eastwood PR, Finucane KE. Volume displaced by diaphragm motion in emphysema. J Appl Physiol 2001; 91: 1913-1923.

23 Aliverti A, Ghidoli G, Dellacà RL, Pedotti A, Macklem PT. Chest wall kinematic determinants of diaphragm length by optoelectronic plethysmography and ultrasonography. J Appl Physiol 2003; 94: 621-630.

24 Suga K, Tsukuda T, Awaya H, et al. Impaired respiratory mechanics in pulmonary emphysema: evaluation with dynamic breathing MRI. J Magn Reson Imaging 1999; 10: 510-520.

25 O'Donnell DE, Voduc N, Fitzpatrick M, Webb KA. Effect of salmeterol on the ventilatory response to exercise in chronic obstructive pulmonary disease. Eur Respir J 2004; 24: 86-94. 
26 Man WD, Soliman MG, Gearing J, et al. Symptoms and quadriceps fatigability after walking and cycling in chronic obstructive pulmonary disease. Am J Respir Crit Care Med 2003; 168: 562-567.
27 Pepin V, Saey D, Whittom F, LeBlanc P, Maltais F. Walking versus cycling: sensitivity to bronchodilation in chronic obstructive pulmonary disease. Am J Respir Crit Care Med 2005; 172: 1517-1522. 